\title{
Relationship between prostaglandin-induced luteolysis and temporary inhibition of myometrial activity in late pregnant cows with ear implants containing progestagen
}

\author{
B. P. M. Janszen, M. M. Bevers, M. M. Ravenshorst, G. C. van der \\ Weijden, S. J. Dieleman and M. A. M. Taverne \\ Department of Herd Health and Reproduction, University of Utrecht, Yalelaan 7, 3508 TD Utrecht, \\ The Netherlands
}

\begin{abstract}
The influence of luteolysis on myometrial activity in late pregnant cows was studied by measuring electromyographic (EMG) activity and concentrations of progesterone and 13,14dihydro-15-keto-prostaglandin $\mathrm{F}_{2 \alpha}$ (PGFM) in maternal arterial plasma of five cows. Application of two ear implants containing progestagen at day 261 of gestation was followed by an injection of a luteolytic dose of a prostaglandin $\mathrm{F}_{2 \alpha}\left(\mathrm{PGF}_{2 \alpha}\right)$ analogue $(\mathrm{PG})$ on day 264. Calving was initiated by removal of the implants and a single injection of $5 \mathrm{mg}$ flumethason on day 270 . All calves were born alive at a mean interval of $36 \mathrm{~h}$. After $4 \mathrm{~h}$ of hyperactivity immediately following the injection of PG, myometrial activity was almost completely absent for $20 \mathrm{~h}$; before luteolysis the total duration of EMG activity was $7.21 \pm 0.31 \mathrm{~min} \mathrm{~h}^{-1}$ (mean $\pm \mathrm{SEM}$ ), during the $4 \mathrm{~h}$ after PG $23.61 \pm 3.40 \mathrm{~min}^{-1}$, and during inhibition $2.70 \pm 0.87 \mathrm{~min} \mathrm{~h}^{-1}$. After the last period, EMG activity recurred and reached values of $14.52 \pm 3.07$ and $11.17 \pm 2.87 \mathrm{~min}^{-1}$, on days 265 and 269 , respectively. Concentrations of progesterone in maternal plasma decreased from 4.17 to $1.14 \mathrm{ng} \mathrm{ml}^{-1}$ within $12 \mathrm{~h}$ after PG, whereas concentrations of PGFM in plasma remained low, varying from 15 to $30 \mathrm{pg} \mathrm{ml}^{-1}$. After removal of the implants and injection of flumethason on day 270, EMG activity increased without an inhibitory phase and reached maximum values around the time of expulsion of the calves. PGFM concentrations gradually increased to $40 \mathrm{pg} \mathrm{ml}^{-1}$ at $16 \mathrm{~h}$ after removal of the implants and injection of flumethason; there was then a steep increase to mean concentrations of $200 \mathrm{pg} \mathrm{ml}^{-1}$ during expulsion of the calf. These results indicate that a factor, released during luteolysis, exerts an inhibitory effect on the myometrium.
\end{abstract}

\section{Introduction}

In the last trimester of gestation in ruminants, the myometrium displays a specific pattern of EMG activity. In cows, periods of activity last for two to twenty minutes, appear at a frequency of 12 per $24 \mathrm{~h}$ and are separated by long periods of rest (Janszen et al., 1990a). After initiation of parturition, this relatively quiescent pattern of myometrial activity changes into a parturient type of activity, characterized by short bursts of activity, separated by short periods of rest. In a study in cows, a temporary loss of uterine tone was found as a typical marker for the onset of parturition (Rüsse, 1964). A period of myometrial quiescence could also be demonstrated by EMG recordings in sheep (Toutain et al, 1983), goats (Taverne and Scheerboom, 1985) and cows (Janszen $e t$ al., 1990a) and immediately preceded the onset of the parturient type of myometrial activity. In the last mentioned study parturition had been induced by a single injection of flumethason on day 270 of gestation. Because the period of myometrial quiescence, which lasted for $9 \mathrm{~h}$, coincided with

Received 13 April 1992 the flumethason-induced decrease of progesterone, a causal relationship between luteolysis and myometrial inhibition was suggested (Janszen et al., 1990a). In the study reported here, luteolysis and parturition were separated. Implants containing progestagen were used to replace progesterone to maintain pregnancy after premature induction of luteolysis in cows provided with uterine EMG electrodes. With this approach the following two questions were addressed. Does myometrial inhibition occur when luteolysis is induced in a late gestational, non-parturient cow? Does a period of myometrial inhibition occur when parturition is induced seven days after luteolysis?

\section{Materials and Methods}

Animals and treatments

Five pluriparous Dutch-Friesian cows were subjected to surgery between days 249 and 254 of gestation. Surgical details have been described by Taverne et al. (1988) and can be summarized as follows. Anaesthesia was induced in the cow by i.v. 
infusion of a mixture of guaifenesium and thiopental natrium and maintained, after intubation, with fluothane in oxygennitrous oxide. The uterus was approached by a midventral laparotomy. Two bipolar silver electrodes (Naaktgeboren et al., 1973) were sutured on the surface of the pregnant horn, one close to the uterotubal junction and the other as far caudal as possible to the uterine bifurcation. The electrode wires were exteriorized through the left lateral abdominal wall. After repositioning of the cow, the left circumflex artery and vein were cannulated and polyvinyl catheters were introduced with their tips in the dorsal aorta and vena cava caudalis, respectively. Wires and catheters were tunnelled subcutaneously to the most dorsal area of the sublumbar fossa, where they were fixed to the skin in a bag containing alcohol. The day after surgery, the cows were placed in a pen and the catheters were flushed and stored in alcohol in a closed box beside the cow's pen. Daily i.m. injections of pencillin $\left(6 \times 10^{6} \mathrm{iu}\right)$ and streptomycin $(6 \mathrm{~g})$ were given for 5 days following surgery. This protocol has been evaluated and approved in advance by the Ethical Committee of the University of Utrecht, according to the Dutch Animal Experiments Act.

\section{Experimental design}

Janszen et al. (1990b) demonstrated that pregnancy could be maintained for more than six days after luteolysis induced by PG by means of two ear implants containing progestagen. After removal of the implants, normal parturition occurred and healthy calves were born. In the study reported here this model was used to separate luteolysis and parturition. The experimental design is shown (Fig. 1). After recovery from surgery for at least five days, EMG was recorded and blood samples were taken from day 259 of gestation. On day 261, cows received an ear implant containing $3 \mathrm{mg}$ norgestomet in each ear (Crestar: Intervet, Boxmeer). On day 264, $2 \mathrm{ml}$ of a synthetic prostaglandin $F_{2 a}$ analogue (Prosolvin: Intervet) was injected i.m. to induce luteolysis. On day 270 both ear implants were removed and an i.m. injection of $5 \mathrm{mg}$ flumethason (Cortexilar: Syntex Agribusiness, Zoetermeer) was given. Blood samples were taken twice daily at 08.00 and $20.00 \mathrm{~h}$ from day 259 until parturition. In addition, samples were taken at intervals of $2 \mathrm{~h}$ from $4 \mathrm{~h}$ before to $32 \mathrm{~h}$ after $\mathrm{PG}$ treatment, and from the flumethason injection until parturition.

\section{EMG measurements}

Recording equipment was situated in a room adjacent to the cow. Recordings were made continuously throughout the study, except on days 261,262, 267 and 268 when registrations were made only between 08.00 and $20.00 \mathrm{~h}$. Signals were amplified and filtered (EMT 12, Elema-Schönlander, Stockholm) with a high cut-off frequency of $30 \mathrm{~Hz}$ and a time constant of $0.03 \mathrm{~s}$ and registered by two paper recorders: one (Mingograf 81, Elema-Schönlander, Stockholm) with a constant chart speed of $2.5 \mathrm{~mm} \mathrm{~s}^{-1}$, the other (Rec. I4 Mijnhardt, Bunnik) with a constant chart speed of $1 \mathrm{~cm} \mathrm{~min}{ }^{-1}$. The slow paper speed recordings were used to measure frequency (per hour) of periods of myometrial electrical activity (contractures, Harding et al., 1982) and total duration of activity per $\mathrm{h}\left(\mathrm{min} \mathrm{h}^{-1}\right)$ from the beginning of the experiment until flumethason injection. Recordings made at the high chart speed were used to quantify total duration of EMG activity $\left(\mathrm{s} \mathrm{h}^{-1}\right)$ during induction of calving. In this type of analysis, short periods $(5-30 \mathrm{~s})$ of electrical quiescence between bursts of spikes could be more accurately excluded.

\section{Hormone analysis}

Blood samples were collected in ice-cooled heparinized tubes; those for PGFM analysis contained $1 \%(\mathrm{w} / \mathrm{v})$ acetylsalicylic acid in $0.3 \mathrm{~mol} \mathrm{EDTA} 1^{-1}$ (pH 7.4). All samples were centrifuged $(1500 \mathrm{~g})$ within $20 \mathrm{~min}$ of collection and stored at $-20^{\circ} \mathrm{C}$ until assayed. Concentrations of progesterone in maternal arterial plasma were estimated by a direct solid-phase ${ }^{125} \mathrm{I}$ radioimmunoassay method (Coat-A-Count TKPG: Diagnostic Products Corporation, Los Angeles, CA) in $100 \mu \mathrm{l}$ samples in duplicate without extraction according to the manufacturer and as described by Dieleman and Bevers (1987). Sensitivity of the assay was $47 \mathrm{pg} \mathrm{ml}^{-1}$, derived from the $90 \%$ relative binding value; the interassay coefficient of variation was $11 \%(n=16)$ and the intra-assay variation was $7.5 \%(n=20)$. Concentrations of PGFM in maternal arterial blood were estimated by a homologous doubleantibody radioimmunoassay according to Granström and Kindahl (1982). Briefly, an antibody raised in rabbits to a PGFM-BSA conjugate (a gift from $\mathrm{H}$. Kindahl, Uppsala) was used at a final concentration of $1: 28000$. The tracer was 13,14-dihydro-15keto- $\left[5,6,8,9,11,12,14(n)-{ }^{3} \mathrm{H}\right]$-prostaglandin $\mathrm{F}_{2 \alpha}$ (Amersham International, UK), and 13,14-dihydro-15-keto-PGF ${ }_{2 \alpha}$ (Sigma, St Louis, MO) was used as a standard (range $0.4-400 \mathrm{pg}$ ). The sensitivity of the assay was $15 \mathrm{pg} \mathrm{ml}^{-1}$, derived from the $90 \%$ relative binding value. The intra- and interassay coefficients of variation were 11.0 and $24.3 \%(n=20)$, respectively. The crossreaction with 15 -keto-PGF $1 \alpha$ was $42 \%$, with 15 -keto-PGF $2 \alpha$ $16 \%$, with 13,14 -dihydro-PGF $2 a 4 \%$, according to Granström and Kindahl (1982).

\section{Data analysis}

Experimental data (EMG characteristics and plasma hormone concentrations) were analysed for six consecutive periods $(A-F)$ during the protocol (Fig. 1). Periods A, B, C, D and E each cover $24 \mathrm{~h}$, and period $\mathrm{F}$ starts with the removal of the implants and the injection of flumethason and ends with the expulsion of the calf. Frequency of contractures, total duration of EMG activity and mean concentrations of progesterone and PGFM in arterial samples obtained during periods $A$ to $E$ were calculated for individual cows; thereafter, overall mean values $( \pm S E M)$ for five cows were calculated for each period. During period $F$ this procedure was used on data from three cows, from which complete datasets were available. Period $C$, which started with an injection of $P G$, was subdivided after EMG recordings had been analysed; a period of $4 \mathrm{~h}$ immediately after injection (C1) and a remaining period of $20 \mathrm{~h}(\mathrm{C} 2)$. Differences among periods $\mathrm{A}$ to $E$ in Table 1 were compared for statistical significance by Bonferroni's $t$ test (Gill, 1978). 


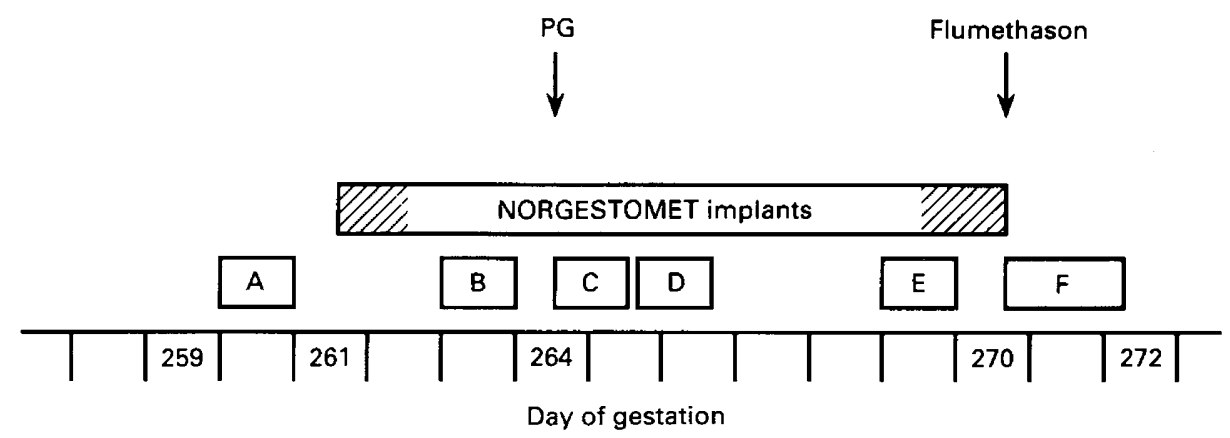

Fig. 1. Experimental design. The letters $A-F$ represent the periods of sampling and EMG recordings that were used in the calculations. PG $\downarrow$ indicates the injection of a PGF $F_{2 a}$ analogue, and Flumethason $\downarrow$ the injection of $5 \mathrm{mg}$ flumethason.

Table 1. Mean ( \pm SEM) total duration of EMG activity, contracture frequency and arterial plasma concentrations of progesterone and 13,14-dihydro-15-keto-prostaglandin $\mathrm{F}_{2 \alpha}$ (PGFM) on days $260(A), 263(B), 264(C 2), 265(D)$ and day $269(\mathrm{E})$

\begin{tabular}{lcccc}
\hline Period & $\begin{array}{c}\text { Activity } \\
\left(\mathrm{min} \mathrm{h} \mathrm{h}^{-1}\right)\end{array}$ & $\begin{array}{c}\text { Contractures } \\
\left(\mathrm{h}^{-1}\right)\end{array}$ & $\begin{array}{c}\text { Progesterone } \\
\left(\mathrm{ng} \mathrm{ml}^{-1}\right)\end{array}$ & $\begin{array}{c}\text { PGFM } \\
\left.(\mathrm{pg} \mathrm{ml})^{-1}\right)\end{array}$ \\
\hline A & $10.97 \pm 1.23$ & $0.95 \pm 0.09$ & $4.17 \pm 0.21$ & $25.8 \pm 4.5$ \\
$\mathrm{~B}$ & $7.21 \pm 0.31$ & $0.65 \pm 0.03$ & $3.50 \pm 0.30$ & $22.2 \pm 2.7$ \\
$\mathrm{C} 2$ & $2.70 \pm 0.87^{*}$ & $0.28 \pm 0.06^{*}$ & $1.14 \pm 0.04^{*}$ & $22.2 \pm 3.1$ \\
$\mathrm{D}$ & $14.52 \pm 3.07$ & $1.28 \pm 0.23$ & $0.85 \pm 0.05$ & $25.8 \pm 4.8$ \\
E & $11.17 \pm 2.87$ & $0.89 \pm 0.19$ & $0.69 \pm 0.09$ & $28.6 \pm 5.7$ \\
\hline
\end{tabular}

${ }^{*} P<0.05$ compared with $\mathrm{B}$ and $\mathrm{D}$.

$n=5$ for periods $A-D$ and $n=4$ for period $E$.

\section{Results}

Each of the five cows remained pregnant until removal of the norgestomet implants. All calves were born alive at a mean interval of $36.2 \pm 0.66 \mathrm{~h}$ after the removal of the implants and the injection of flumethason. In one animal it was observed on day 269 that one of the two implants had been lost. It was decided to remove the other implant and give the injection of flumethason one day earlier than had been planned in the protocol. Data from this animal were not included in the calculations for periods $\mathrm{E}$ and $\mathrm{F}$.

\section{$E M G$ activity and hormonal changes around injection of the prostaglandin analogue}

Myometrial activity, plasma progesterone and PGFM concentrations during periods $A$ and $B$ were not significantly different (Table 1). During a period of $4 \mathrm{~h}(\mathrm{CI})$ immediately following the PG injection, uterine EMG activity increased: total duration measured $23.63 \pm 3.40 \mathrm{~min} \mathrm{~h}^{-1}$ and contracture frequency (per hour) was $1.90 \pm 0.19$ (Fig. 2). Thereafter EMG activity significantly decreased because contractures nearly disappeared for 18-20 h (period C2). During period C, plasma progesterone concentrations decreased significantly to mean values just above $1 \mathrm{ng} \mathrm{ml}^{-1}$, whereas no significant changes of the PGFM levels were detected. Between 24 and $48 \mathrm{~h}$ after PG injection, contractures reappeared and total duration of EMG activity gradually increased and reached values that were temporarily even higher than before luteolysis. The overall mean values of myometrial activity during periods $\mathrm{A}$ and $\mathrm{E}$ were not significantly different.

\section{EMG activity and hormonal changes around parturition}

Data from two animals were not used: one cow lost one of the two ear implants after period D, while in a second cow artefacts in the recordings made quantitative analysis of EMG activity impossible. However, it was obvious that in none of the remaining three cows did a period of myometrial inhibition occur after injection of flumethason and removal of the implants (Fig. 3). The late gestational pattern evolved into a parturient pattern without a quiescent period. About $16 \mathrm{~h}$ after flumethason, total duration of EMG activity started to increase, concurrently with a steady increase of the plasma PGFM concentrations. Both reached maximum values around the time of expulsion of the calf $20 \mathrm{~h}$ later. Concentrations of progesterone in plasma were low and did not change significantly during period $F$.

\section{Discussion}

The results of this study demonstrate that the effect of a luteolytic dose of a prostaglandin analogue on the myometrium of late pregnant cows is twofold. First, uterine EMG activity is stimulated for about $4 \mathrm{~h}$, mainly because of a doubling of the frequency of contractures. A similar, temporary stimulation of the myometrium has been found before in studies where prostaglandins were used to induce luteolysis and parturition in cows (Zerobin et al., 1975) and pigs (Randall, 1990). Second, a uterine inhibiting effect was observed. The almost complete inhibition was characterized by the disappearance of contractures for about $20 \mathrm{~h}$. During this period, concentrations of progesterone in peripheral plasma rapidly declined. This second effect has not been reported before during prostaglandininduced calvings. However, it is additional to our previous findings (Janszen et al., 1990b), which showed a period of myometrial quiescence after a single injection of flumethason at 


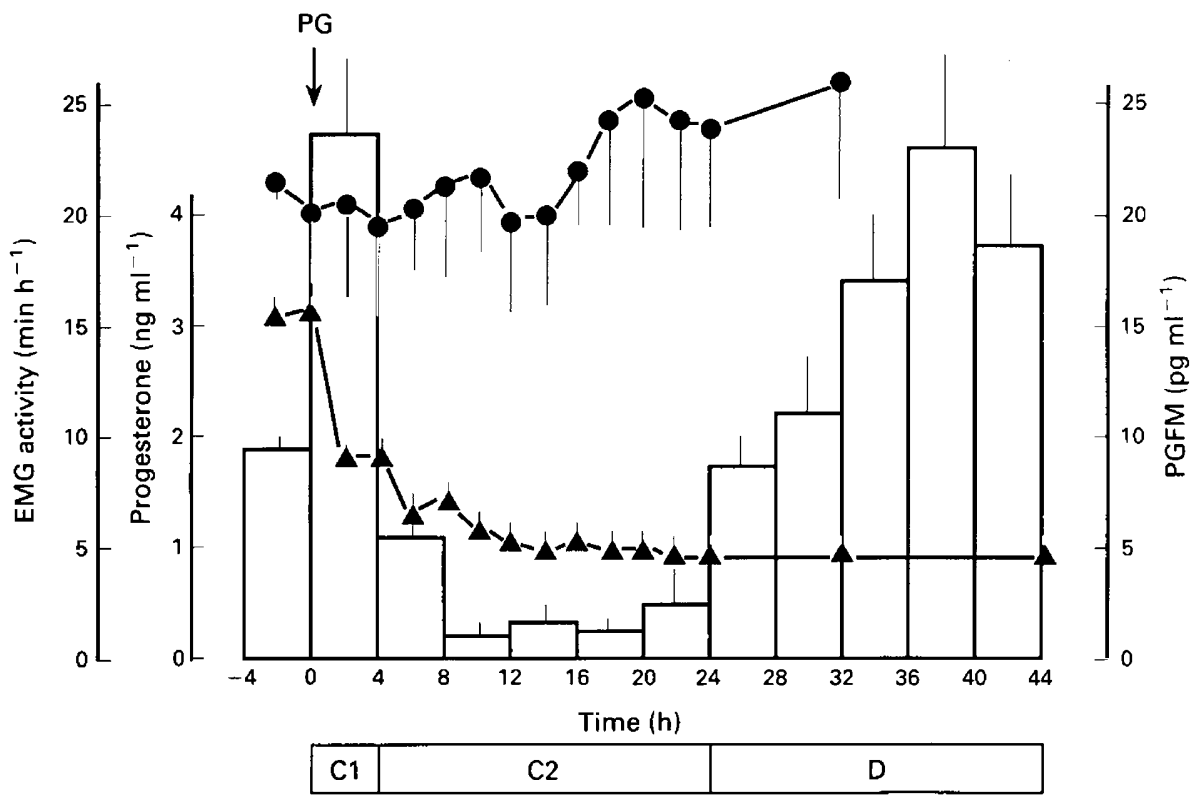

Fig. 2. Mean ( \pm SEM) concentrations of PGFM $(\boldsymbol{O})$ and progesterone $(\boldsymbol{\Delta})$ in matemal plasma and mean duration of EMG activity ( $\square$ ) after injection of a PGF ${ }_{2 \alpha}$ analogue (PG) on day 264 of gestation $(n=5)$.

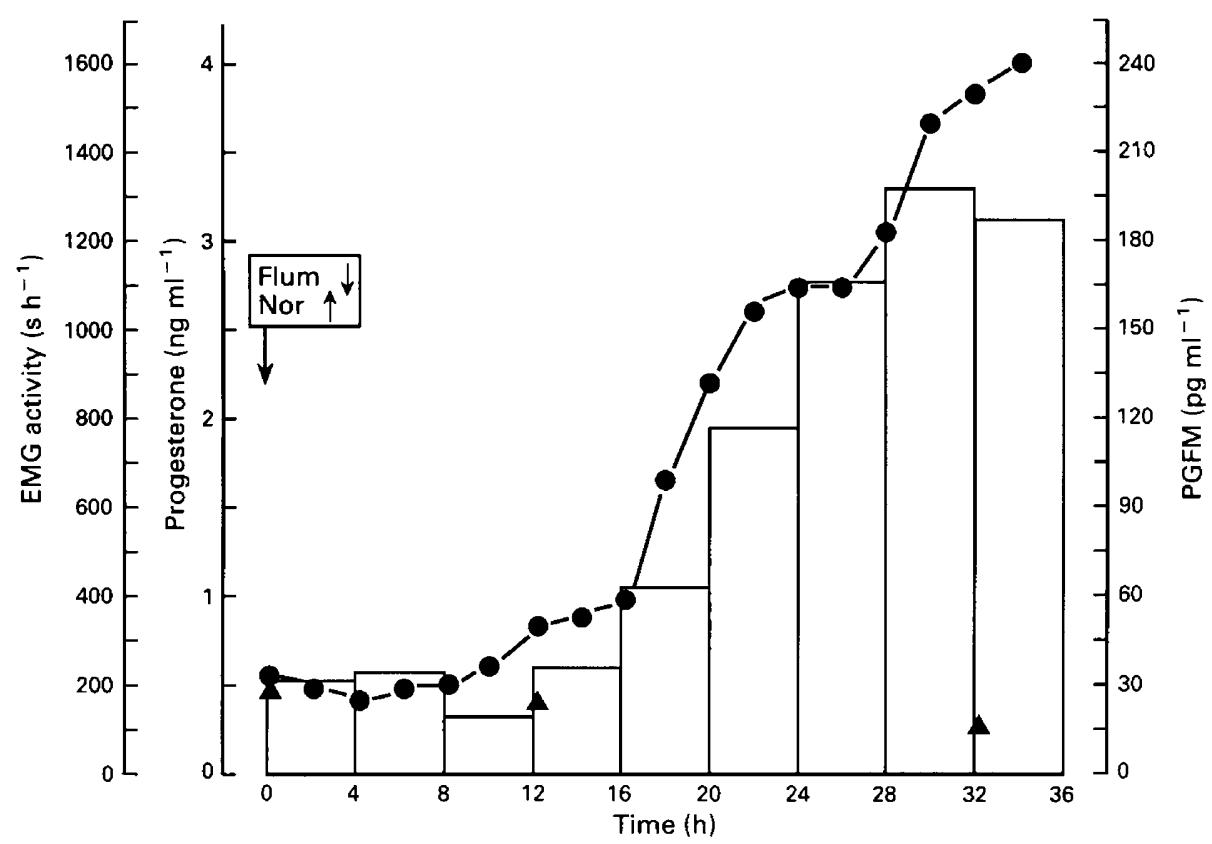

Fig. 3. Mean total duration of EMG activity $(\square)$ and mean plasma concentrations of PGFM ( $)$ and progesterone $(\boldsymbol{\Delta})$ in three cows after injection of $5 \mathrm{mg}$ flumethason (Flum $\downarrow$ ) and removal of the norgestomet implants (Nor $\uparrow$ ).

induction of parturition in late pregnant cows. In addition, in the last mentioned study, uterine inhibition coincided with the period of luteal regression. In sheep (Toutain $e t$ al., 1983) and goats (Taverne and Scheerboom, 1985), a temporary inhibition of the myometrium also occurs and immediately precedes the onset of the parturient pattern of uterine EMG activity, suggesting a relationship with the rapid prepartum progesterone decline.
Two results of the study reported here strongly support the suggestion made by Janszen et al. (1990b) that an unknown factor, released during regression of the corpus luteum, is responsible for myorelaxation. First, uterine inhibition occurred only temporarily because contractures reappeared during period D and persisted as long as pregnancy was maintained by the progestagen replacement therapy. Second, inhibition was not observed for a second time when calving was finally induced by 
removal of the implants and injection of flumethason. The latter finding excludes the possibility that hormonal changes in the uterus associated with the onset of calving, such as an increased prostaglandin production, are responsible for the temporary inhibition. The opposite seems to be true, as the prepartum increase of PGFM concentrations in the earlier study apparently shortened the period of quiescence $(8.8 \mathrm{~h}$; Janszen et al., 1990a, as opposed to $19 \mathrm{~h}$ in the study reported here).

In ruminants prepartum myometrial inhibition coincides with a period during which preparatory functional changes take place within the cervix and the myometrium (Taverne, 1992). In the present study, in which myometrial inhibition and calving were separated by several days, the course of parturition was normal and the calves were born alive. This could suggest that the correct timing of the inhibition period is not essential for successful delivery in cows. It is also possible that it is of no physiological importance, but is merely a side effect of luteolysis. Uncoupling of luteolysis and parturition in pigs resulted in prolonged duration of farrowing and increased rates of stillbirth (Taverne et al., 1982). Incorrect timing of relaxin release is thought to be responsible.

The cause of the temporary inhibition of myometrial activity during luteolysis in cows remains to be explored. If relaxin plays a role, an effect on cervical softening during and after induced luteolysis (for review see Taverne, 1992) can be expected in experiments using the protocol of the present study.

We are grateful to J. van de Broek for help with the statistical analysis, to H. A. van Oord, F. van Kooy and S. H. J. Mook for technical assistance, and to $\mathrm{W}$. Bes for patiently preparing the figures.

\section{References}

Dieleman SJ and Bevers MM (1987) Effects of monoclonal antibody against PMSG administered shortly after the preovulatory LH surge on time and number of ovulations in PMSG/PG treated cows Joumal of Reproduction and Fertility $81533-542$
Gill JL (1978) Design and Analysis of Experiments in the Animal and Medical Sciences. Iowa State University Press, Ames

Granström E and Kindahl H (1982) Radioimmunoassay of the major plasma metabolite of $\mathrm{PGF}_{2 a^{\prime}}$ 15-keto-13,14-dihydro-PGF ${ }_{2 \alpha^{\prime}}$ In Methods in Enzymology Vol 86 pp 320-339 Eds WEM Lands and WL Smith. Academic Press, New York

Harding R, Poore ER, Bailey A, Thorburn GD, Jansen CAM and Nathanielsz PW (1982) Electromyographic activity of the nonpregnant and pregnant sheep uterus American Joumal of Obstetrics and Gynecology 142 448-457

Janszen BPM, Knijn $H$, van de Weijden GC, Bevers MM, Dieleman SJ and Taverne MAM (1990a) Flumethason-induced calving is preceded by a period of myometrial inhibition during luteolysis Biology of Reproduction $\mathbf{4 3}$ 466-471

Janszen BPM, Bevers MM, Dieleman SJ, van der Weijden GC and Taverne MAM (1990b) Synchronised calvings after withdrawal of norgestomet implants from cows treated near term with prostaglandin Veterinary Record $127405-407$

Naaktgeboren D, van der Weijden GC, Klopper PJ, Kroon CH, Schoof AG and Taverne MAM (1973) Electrophysiological observations of uterine motility during the oestrous cycle in sheep Journal of Reproduction and Fertility 35 511-518

Randall GCB (1990) Induction of parturition in pigs: short term effects of prostaglandin $\mathrm{F}_{2 \alpha}$ on chronically catheterised fetuses at term Veterinary Record $12661-63$

Rüsse M (1964) Der Geburtsablauf beim Rind Archiv für Experimentelle Veterinär. medicin $19763-870$

Taverne MAM (1992) Physiology of parturition Animal Reproduction Science 28 433-440

Taverne MAM and Scheerboom JEM (1985) Myometrial electrical activity during pregnancy and parturition in the pygmy goat Research in Veterinary Science 38 120-123

Taverne MAM, Bevers MM, Bradshaw JMC, Dieleman SJ, Willemse AH and Porter DG (1982) Plasma concentrations of prolactin, progesterone, relaxin and oestradiol-17 $\beta$ in sows treated with progesterone, bromocriptine or indomethacin during late pregnancy Journal of Reproduction and Fertility 65 85-96

Taverne MAM, Bevers MM, van der Weijden GC, Dieleman SJ and Fontijne P (1988) Concentration of growth hormone, prolactin and cortisol in fetal and maternal blood and amniotic fluid during late pregnancy and parturition in cows with cannulated fetuses Animal Reproduction Science 17 51-59

Toutain PL, Garcia-Villar R, Hanzen C and Ruckebusch Y (1983) Electrical and mechanical activity of the cervix in the ewe during pregnancy and parturition Journal of Reproduction and Fertility 68 195-204

Zerobin K, Jöchle W, Döbeli M, Steingruber C and Becker M (1975) Die Induktion der Geburt beim Rind mittels Prostaglandin $\mathrm{F}_{2 \alpha^{\prime}}$ gemessen am klinischen Verlauf, dem motorischen Verhalten des Uterus und dem Progesteronblutspiegel Schweizerisches Archiv für Tierheilkunde 117 219-241 